\title{
Genetic and Pathological Diversity Among Xanthomonas Strains Responsible for Bacterial Spot on Tomato and Pepper in the Southwest Indian Ocean Region
}

\author{
A. A. Hamza, I. Robène-Soustrade, E. Jouen, L. Gagnevin, and P. Lefeuvre, Research Plant Pathologists, 97410 \\ Saint Pierre, La Réunion, France; F. Chiroleu, Statistician, CIRAD, UMR Peuplements Végétaux et Bioagresseurs \\ en Milieu Tropical CIRAD-Université de la Réunion, Pôle de Protection des Plantes, 7, chemin de l'Irat, France; and \\ O. Pruvost, Research Plant Pathologist, 97410 Saint Pierre, La Réunion, France
}

\begin{abstract}
Hamza, A. A., Robène-Soustrade, I., Jouen, E., Gagnevin, L., Lefeuvre, P., Chiroleu, F., and Pruvost, O. 2010. Genetic and pathological diversity among Xanthomonas strains responsible for bacterial spot on tomato and pepper in the southwest Indian Ocean region. Plant Dis. 94:993999.

Bacterial spot of tomato and pepper, a major problem in tropical climates, can be caused by several Xanthomonas genospecies. We examined the genetic and pathological diversity of a collection of 72 strains from the southwest Indian Ocean region as part of a regional research and development program to update inventories of agricultural pests and pathogens. Xanthomonas euvesicatoria, $X$. perforans, $X$. gardneri, and X. vesicatoria were identified in our strain collection. The identification of strains at the species level was consistently achieved by amplified fragment length polymorphism (AFLP) and multilocus sequence analysis (MLSA). Overall, $X$. euvesicatoria was the species recovered prevalently. MLSA data based on four housekeeping genes identified two to three sequence types per genospecies. It suggested that sequence variations primarily consisted of synonymous mutations, although a recombination event spanning several hundred nucleotides was detected for some strains of $X$. euvesicatoria on the atpD gene coding for the F1-F0-ATPase $\beta$ subunit. The pathogenicity of strains was consistent with data found in the literature. Some pathological variations were primarily observed among strains identified as $X$. euvesicatoria. This study provides the first ever comprehensive description of the status of Xanthomonas species that cause bacterial spot of tomato and pepper in the southwest Indian Ocean region.
\end{abstract}

Bacterial spot is an important disease of tomato (Solanum lycopersicum) and pepper (Capsicum spp.) in both tropical and more temperate regions (18). The disease is caused by phenotypically and genetically heterogeneous strains of the genus Xanthomonas. The latest classification (19) suggested that four genospecies (Xantho-

Corresponding author: O. Pruvost

E-mail: olivier.pruvost@cirad.fr

* The $\boldsymbol{e}$-Xtra logo stands for "electronic extra" and indicates that three supplemental tables and three supplemental figures not included in the print edition are available online.

GenBank accession numbers for partial sequences used in the MLSA study are available from GenBank (atpD: EU015202, EU015204, EU015209 to EU015212, EU015214, EU015215, GU322721 to GU322805, HM048893 to HM048896; dnaK: EU015294, EU015296, EU015301 to EU015304, EU015306, EU015307, GU322636 to GU322720, HM048889 to HM048893; efp: FJ376351 to FJ376353, FJ376355, FJ376356, FJ376365, FJ376375, FJ376376, GU322551 to GU322635, HM048885 to HM048888; gyrB: EU015386, EU015388, EU015393, EU015394, EU015395, EU015396, EU015398, EU015399, GU322466 to GU322550, HM048881 to HM048884).

Accepted for publication 8 April 2010.

doi:10.1094/PDIS-94-8-0993

(C) 2010 The American Phytopathological Society monas euvesicatoria, X. gardneri, X. perforans, and $X$. vesicatoria) can cause bacterial spot of tomato and pepper (BSTP). These genospecies differ in host range, leading to the description of four races, T1 to $\mathrm{T} 4$, on tomato accessions (18) and at least nine races on pepper (21). The relationship between species assignment and host range or races for these strains is not straightforward. Some strains are pathogenic to tomato or pepper or both (18). Other genera in the family Solanaceae have been listed as host species. However, this was primarily based on reactions following inoculations, some of which may have been hypersensitive as opposed to compatible reactions (21). Finally, $X$. campestris $\mathrm{pv}$. raphani strains primarily pathogenic to cruciferous plant species are also pathogenic to tomato and pepper after inoculation $(11,49,50)$. Moreover, strains causing outbreaks of leaf spot and wilt disease of tomato in Canada (Ontario) and Russia (North Caucasus) were found to be genetically related to $X$. campestris pv. raphani, making tomato a natural host species for this pathogen $(22,38)$.

Xanthomonads causing BSTP are listed on the A2 list of the European and Mediterranean Plant Protection Organization (EPPO), which means that these pathogens are not widely distributed in the EPPO region and are recommended for regulation as quarantine pests (http://archives.eppo. org/EPPOStandards/PM1_GENERAL/pm1 -02(18)_A1A2_2009.pdf). An accurate identification of strains causing BSTP is of particular importance for surveillance and pest management. Over the last decades, the tools most often used for the molecular typing of xanthomonads causing BSTP included repetitive element (rep)-polymerase chain reaction (PCR), pulsed-field gel electrophoresis, and PCR-restriction fragment length polymorphism of the $h r p B$ region $(8,23,30,46)$. We and others have shown the suitability of amplified fragment length polymorphism (AFLP) and multilocus sequence analysis (MLSA) for identification of xanthomonads at the species and pathovar levels $(2,10,40,51)$. The advantages and limitations of both techniques have been reviewed previously (2). One of these studies (10) hypothesized that the atypical placement of $X$. euvesicatoria within the $X$. axonopodis cluster 9.2 sensu Rademaker et al. likely is a consequence of recombination.

A regional program for plant protection (http://www.prpv.org/) focusing on southwest Indian Ocean (SWIO) territories was initiated in 2003. It was implemented by the Indian Ocean Commission with the following member countries: Comoros, Madagascar, Mauritius, Réunion, and the Seychelles. One of the objectives of the program was to elaborate an updated database of pests and pathogens present in these countries. In this article, we identify the strains causing BSTP at the species level in the SWIO region by using AFLP and MLSA based on four housekeeping genes and assess the infraspecific genetic diversity of each group.

\section{MATERIALS AND METHODS}

Bacterial strains, media, and DNA extraction. In all, 133 strains, including 72 strains from the SWIO region, were studied. Information on bacterial strains is provided in Supplementary Table 1. Strains from the SWIO region were isolated from diseased plant material on yeast-peptoneglucose agar (YPGA; yeast extract, $7 \mathrm{~g}$ liter ${ }^{-1}$; peptone, $7 \mathrm{~g}$ liter $^{-1}$, glucose, $7 \mathrm{~g}$ liter ${ }^{-1}$; agar, $18 \mathrm{~g} \mathrm{liter}^{-1}$; and propiconazole, $20 \mu \mathrm{g} \mathrm{ml}^{-1}$; $\mathrm{pH}$ 7.2) or on $\mathrm{KC}$ semiselective medium (37). Plates were incubated for up to five days at $28^{\circ} \mathrm{C}$. Xanthomonaslike colonies were subcultured on YPGA 
medium. All cultures were stored as lyophiles or at $-80^{\circ} \mathrm{C}$ in Microbank tubes (VWR, Fontenay-sous-Bois, France). For DNA extractions, 24-h-old subcultures on YPGA were used to inoculate yeastpeptone broth. Tubes were incubated for 16 to $18 \mathrm{~h}$ at $28^{\circ} \mathrm{C}$ under agitation. DNA was extracted using the DNeasy blood and tissue kit (Qiagen, Courtaboeuf, France) following the manufacturer's instructions and DNA concentrations were estimated spectrophotometrically (Nanodrop Technologies, Labtech, Palaiseau, France).

AFLP analysis. All strains were subjected to AFLP analysis. Two independent DNA extractions were used for all strains. The type strains of $X$. euvesicatoria (NCPPB 2968), X. gardneri (NCPPB 881), $X$. perforans (NCPPB 4321), and X. vesicatoria (LMG 911) were used as controls in each AFLP experiment. PCR reactions were performed in a GeneAmp PCR system 9700 thermocycler (Applied Biosystems, Courtaboeuf, France). Adaptors and PCR primers were synthesized by Applied Biosystems (Supplementary Table 2).

AFLP analysis was performed as described previously (2). The selective amplifications were performed using unlabeled MspI + 1 (A, C, T, or G) primers and 5'-labeled - SacI + C primers (fluorochromes used: 6-FAM, VIC, NED, and PET, respectively). Electrophoresis was performed in an ABI PRISM-3130XL Genetic Analyzer (Applied Biosystems) using performance-optimized polymer POP-7 at $15,000 \mathrm{~V}$ for about $20 \mathrm{~min}$ at $60^{\circ} \mathrm{C}$, with an initial injection of $69 \mathrm{~s}$. The AFLP fingerprints were analyzed visually using Genemapper software 4.0 (Applied Biosystems). The threshold for assigning a peak was set to 500 relative fluorescence units. The presence and absence of fragments were scored as a binary matrix.

Evolutionary genome divergences (EGDs) were calculated from Dice similarity indices and corrected to account for unobserved substitutions by using the standard Jukes-Cantor model, which assumes equal rates of substitution between all pairs of bases $(28,35)$. EGD values were used as distances to construct a weighted neighbor-joining (NJ) tree $(12,45)$ using the $\mathrm{R}$ statistical package (version 2.9.1; R Development Core team) and the APE package version 2.3 (32). The robustness of the trees was assessed by bootstrap (1,000 resamplings).

MLSA. Four gene portions-atpD, dnaK, efp, and gyrB (2,6,33,51)-were amplified using the BD advantage 2 polymerase mix kit (Clontech, Ozyme, Montigny-Le-Bretonneux, France), as recommended by the manufacturer, using primers shown in Supplementary Table 3. Amplifications were performed in a PE9600 thermocyler (Applied Biosytems) as follows: an initial denaturation at $95^{\circ} \mathrm{C}$ for 3 min was followed by 35 cycles of denaturation for $1 \mathrm{~min}$ at $95^{\circ} \mathrm{C}$, annealing for $1 \mathrm{~min}$ at $66^{\circ} \mathrm{C}$, and extension for $1 \mathrm{~min}$ at $68^{\circ} \mathrm{C}$ and a final extension step at $68^{\circ} \mathrm{C}$ for $7 \mathrm{~min}$. For a small number of straingene combinations, the annealing temperature was modified $\left(63\right.$ to $\left.68^{\circ} \mathrm{C}\right)$ for optimal PCR quality or yield. The amplicons were sequenced by Macrogen or Cogenics (efp) (single-pass double-stranded analysis), using primers shown in Supplementary Table 3 .

DNA sequences for each gene were aligned using the Clustal $\mathrm{W}$ based subalignment tool (48) available in the MEGA 4.1 program (47). The Nei and Gojobori method (29) was used for evaluating the synonymous/nonsynonymous substitution $(\mathrm{Ka} / \mathrm{Ks})$ ratios using the MEGA 4.1 program. The detection of potential recombinant sequences, identification of likely parental sequences, and localization of possible recombination breakpoints were carried out on concatenated sequence alignments by using a set of seven nonparametric detection methods: RDP (24), Geneconv (31), MaxChi (27), Chimera (36), bootscan (25), SiScan (13), and $3 \mathrm{Seq}(5)$, all of which were run in the RDP3 software (26). Analyses were performed with default settings for the different detection methods and a Bonferroni corrected $P$ value cutoff of 0.05 . Recombination events were accepted when detected with three or more detection methods. The breakpoint positions and recombinant sequences inferred for every detected potential recombination event were visually checked and adjusted when necessary by using the extensive phylogenetic and recombination signal analysis features available in RDP3. Maximum likelihood (ML) trees were built for the recombinant and nonrecombinant regions using the PHYML (14) subroutine available in RDP3, using the Kimura 2-parameter model.

Pathogenicity tests. Solanaceous species used for pathogenicity tests included tomato (S. lycopersicum) cv. Marmande and pepper (Capsicum annuum) cvs. Yolo Wonder and Aiguille. Five to seven weekold seedlings were used for inoculation. Strains tested for pathogenicity included the type strain of the four valid Xanthomonas species causing bacterial spot disease and all strains originating from the SWIO region $(n=72)$. Bacterial suspensions containing approximately $1 \times 10^{5} \mathrm{CFU} \mathrm{ml}{ }^{-1}$ were obtained by 10 -fold dilutions in 0.01 M sterile Sigma 7-9 buffer (pH 7.2; Sigma, Saint-Quentin Fallavier, France) of spectrophotometrically adjusted suspensions (0.05 optical density at $600 \mathrm{~nm}$ : approximately $1 \times 10^{8} \mathrm{CFU} \mathrm{m}{ }^{-1}$ ) prepared from 18-h-old cultures on YPGA. Sterile Sigma 7-9 buffer was used as the inoculum for negative controls. Suspensions were infiltrated $\left(0.3\right.$ to $\left.0.4 \mathrm{~cm}^{2}\right)$ into the abaxial side of the mesophyll of young leaves using a needleless syringe. For each strain, six inoculation points were performed on one leaf from three different plants. Plants were placed in growth chambers at $28 \pm$ $1{ }^{\circ} \mathrm{C}$ (day) and $26 \pm 1{ }^{\circ} \mathrm{C}$ (night) and $80 \pm$ $5 \%$ relative humidity for 25 days with a photoperiod of $12 \mathrm{~h}$. Leaves were checked daily for lesion development. Bacterial population sizes in symptomatic plants were assessed for the type strain of each species causing BSTP and at least one representative of each AFLP haplotype among strains originating from the SWIO region. Population sizes were determined at the end of experiments ( 25 days after inoculation [dai]) from single lesions (at least 10 replicates were analyzed) using a Spiral System device (Interscience) on KC semiselective medium (37), except for strain NCPPB 881, for which slower growth was recorded on $\mathrm{KC}$ medium and the NCTM1 semiselective medium was used (44). Bacterial population sizes were based on enumeration of Xanthomonaslike colonies. All experiments were replicated at least once. Bacterial population sizes were log-transformed to stabilize sample variances prior to statistical analysis using the $\mathrm{R}$ statistical package. The Bartlett test used for assessing variance homogeneity indicated that this criterion was not met for some data sets. Therefore, nonparametric tests (Kruskal-Wallis and Wilcoxon-Mann-Whitney tests) were performed. For the latter test, adjusted $P$ values for multiple comparisons were calculated using the Benjamini and Holberg method (4).

The three reference strains of $X$. campestris pv. raphani were checked for pathogenicity to radish (Raphanus sati$v u s)$. Spray inoculations to radish cv. rond Gaudry 2 and kocto leaves were performed using bacterial suspensions containing approximately $1 \times 10^{8} \mathrm{CFU} \mathrm{ml} \mathrm{m}^{-1}$ and prepared as described above. Environmental parameters and visual assessment of disease development were as described above.

\section{RESULTS}

AFLP analysis. EGD values calculated for each pair of the type strain of species causing BSTP or the pathotype strain of $X$. campestris pv. raphani were $>0.100 \mathrm{nu}-$ cleotide substitutions per site (nsps), except for X. euvesicatoria and $X$. perforans, which differed only by 0.045 nsps. All strains originating from the SWIO region displayed low EGD values (i.e., $<0.030$ nsps) with one of the type strain of the genospecies associated with BSTP and, thus, were easily identified at the species level. Computation of EGDs between SWIO-originating strains and the type strain of all valid Xanthomonas spp. confirmed that no misidentification had occurred (data not shown). In the SWIO region, we identified strains that were genetically related to $X$. euvesicatoria $(n=$ 47), X. gardneri $(n=9), X$. perforans $(n=$ $11)$, and $X$. vesicatoria $(n=5)$ (Fig. 1). However, none were related to $X$. campestris pv. raphani. The geographical distribu- 
tion of species is shown in Figure 2. Overall, $X$. euvesicatoria was the prevalent species $(65 \%)$ among the SWIO strains studied. The largest diversity was recorded in Réunion, with the identification of three species: X. euvesicatoria, X. gardneri, and $X$. vesicatoria.

$\mathrm{NJ}$ trees were built for assessing the within-species genetic diversity and relationships among strains. Branches connecting groups of $X$. gardneri strains were characterized by low $(<80 \%)$ bootstrap values. A single strain (ICMP 7383) originating from New Zealand was markedly different from other $X$. gardneri strains. $X$. gardneri strains that were identified from samples originating from Réunion Island clustered as a nonrobust group (Supplementary Figure 1).

Given the relatively low EGD value between X. euvesicatoria and X. perforans, the genetic diversity of both species was assessed concomitantly and is shown in Supplementary Figure 2. Strains identified as $X$. perforans in the Seychelles and Mayotte islands clustered with the $X$. perforans type strain and formed a robust group (with a bootstrap of $100 \%$ ). Within this cluster, two robust groups of strains originating from Mayotte and the Seychelles were identified with strong bootstrap values. All strains identified as $X$. euvesicatoria grouped as a robust cluster (with a bootstrap of $100 \%$ ). Most strains within the $X$. euvesicatoria species were separated by relatively short branches supported by low $(<80 \%)$ bootstrap values. However, a group containing six strains that originated from India $(n=4)$ and Grenada $(n=2)$ clustered as a robust group with a bootstrap value of $100 \%$. Strain ICMP 8037 from Brazil was characterized by a long branch due to the presence of one private marker and the absence of seven markers present in all other $X$. euvesicatoria strains (Supplementary Figure 2). Among strains originating from the SWIO region, strains originating from Mauritius formed a robust group (with a bootstrap of 90\%) that also contained strain CFBP 5618 from the United States. Some of the strains originating from the Comoros (LA88-1 to 6) formed another robust group with a maximal bootstrap value. Other strains identified as X. euvesicatoria and originating from the Comoros and Réunion scattered within the $\mathrm{NJ}$ tree.

In contrast, a strong structure with tree branches supported by bootstrap values of $100 \%$ was shown for $X$. vesicatoria, leading to the identification of two groups of strains (Supplementary Figure 3). Most strains clustered in the first group, including the type strain. Strains originating from Madagascar and Réunion clustered in a second group, which also contained two strains originating from Europe (France and Italy). Some strains from Madagascar and Réunion had an identical AFLP fingerprint.
MLSA. Analyzed sequence lengths ranged from $387 \mathrm{bp}$ (efp) to $771 \mathrm{bp}$ (gyrB), leading to a total of 2,667 bp for the four regions sequenced. The average $\mathrm{Ka} / \mathrm{Ks}$ for all gene portions was $<<1$, confirming that synonymous mutations markedly exceeded nonsynonymous mutations.

Interestingly, six recombination detection algorithms significantly detected a recombination event in the $a t p D$ gene portion, with beginning and ending breakpoints estimated at position 1 and 309 , respectively. The tree derived from the alignment of the atpD region showed an evidence of recombination for most (45/51) strains of $X$. euvesicatoria (sequence type [ST] E1 and ST E3), which had a marked sequence divergence with $X$. perforans (all STs) and X. euvesicatoria ST E2. Because interspecies recombination can distort phylogenetic relatedness among similar species, two ML trees describing the genetic relatedness among strains in the recombinant region (Fig. 3A) and in the concatenated dataset but the recombinant region (Fig. 3B), respectively, were computed. $X$. euvesicatoria and $X$. perforans were closely related based on the tree derived from the alignment of the concatenated dataset but the recombinant region (Fig. 3B), consistent with AFLP data.

All species associated with BSTP could be distinguished by MLSA, consistent with AFLP data. Based on concatenated data, three STs were identified among

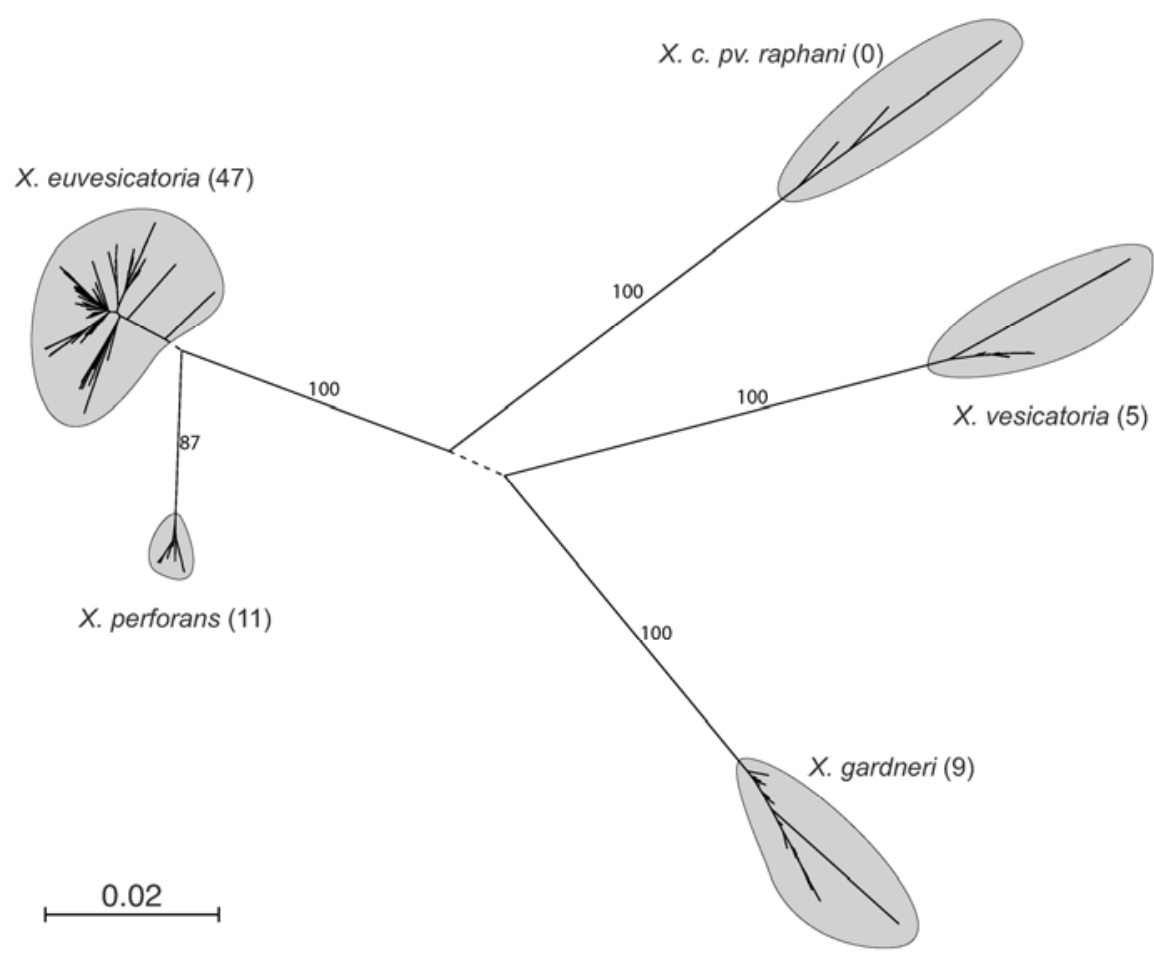

Fig. 1. Neighbor-joining tree derived from evolutionary genome divergences (28) showing the relationships among strains responsible for bacterial spot of tomato and pepper based on 485 amplified fragment length polymorphism markers. Branches with bootstrap values $<80 \%$ are represented by dotted lines. Bootstrap values $\geq 80 \%$ are shown along the corresponding branches. For each species, numbers in parentheses indicate the numbers of strains isolated in the southwest Indian Ocean region. strains of $X$. euvesicatoria. Most strains (37/51) were ST E1, including the type strain. ST E2 comprised six strains originating from India and Grenada, consistent with AFLP data. This group was markedly different from other X. euvesicatoria STs based on data derived from atpD, because recombinant region. On other gene portions, it also differed from other STs, based on one to three single-nucleotide polymorphisms (SNPs). ST E3 was only identified among some of the strains originating from Mauritius and Réunion. They differed from ST E1 by only one SNP on the atpD gene portion (outside the recombinant region). Similarly, three STs were identified among strains of $X$. perforans. ST P1 comprised the type strain of $X$. perforans and most strains originating from the Seychelles. A single strain from this country (LB102-2; ST P2) differed from ST P1 strains based on one SNP on the gyrB gene portion. ST P3 comprised strains originating from Mayotte and differed from STs P1 and P2 based on one SNP on the efp gene portion. All strains of $X$. gardneri originating from the SWIO region had sequences that were totally identical to that of the type strain of this species (ST G1). ST G2 only comprised strain ICMP 7383 and its sequence differed by 12 SNPs scattered on the gyrB locus (that were not identified as a putative recombination event by RDP3). Most strains of $X$. vesicatoria had sequences that were totally identical to that of the type strain, whatever the gene portion (ST V1). it was the only one that did not show the 


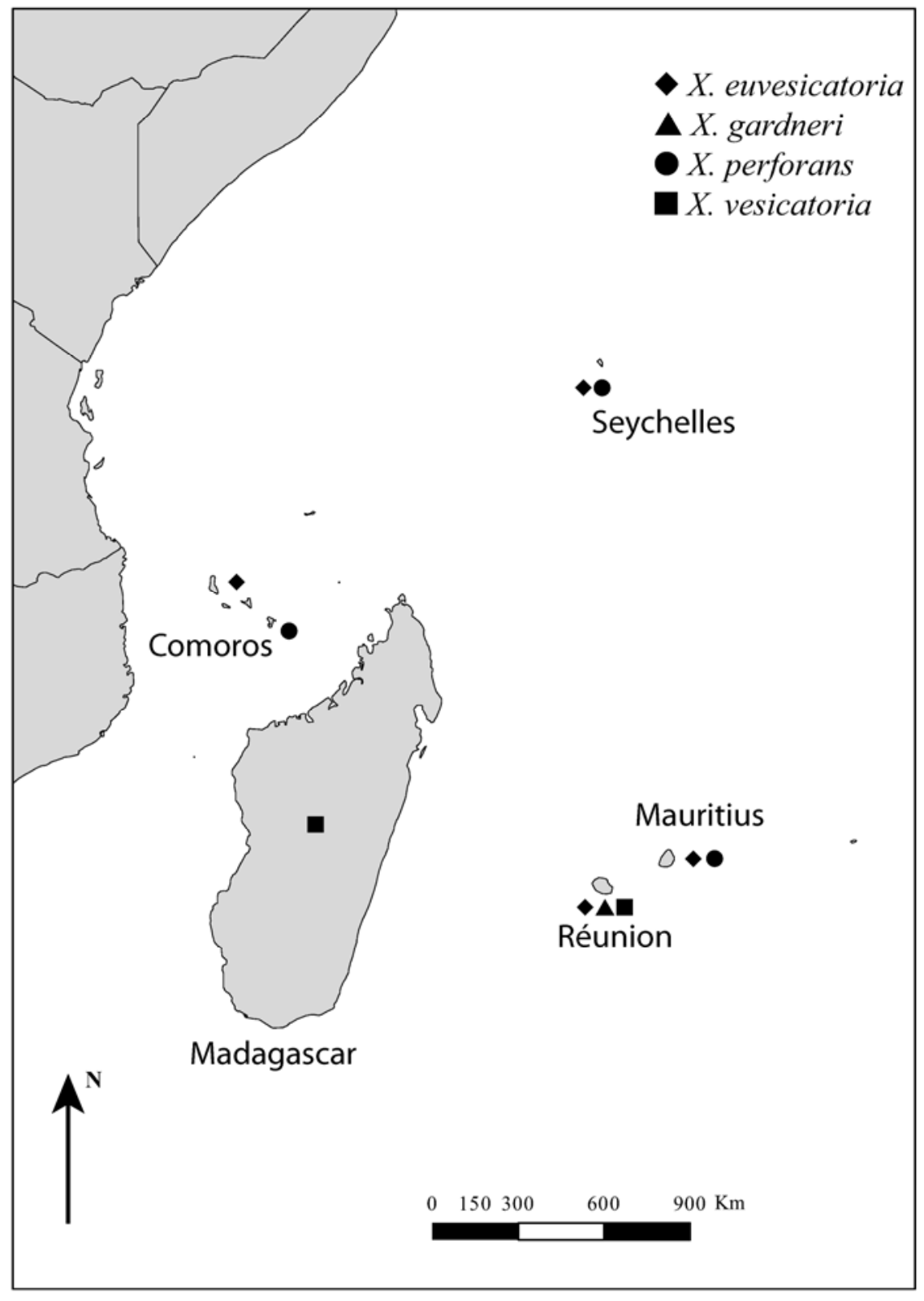

Fig. 2. Distribution map of the Xanthomonas genospecies responsible for bacterial spot of tomato and pepper in the southwest Indian Ocean region.

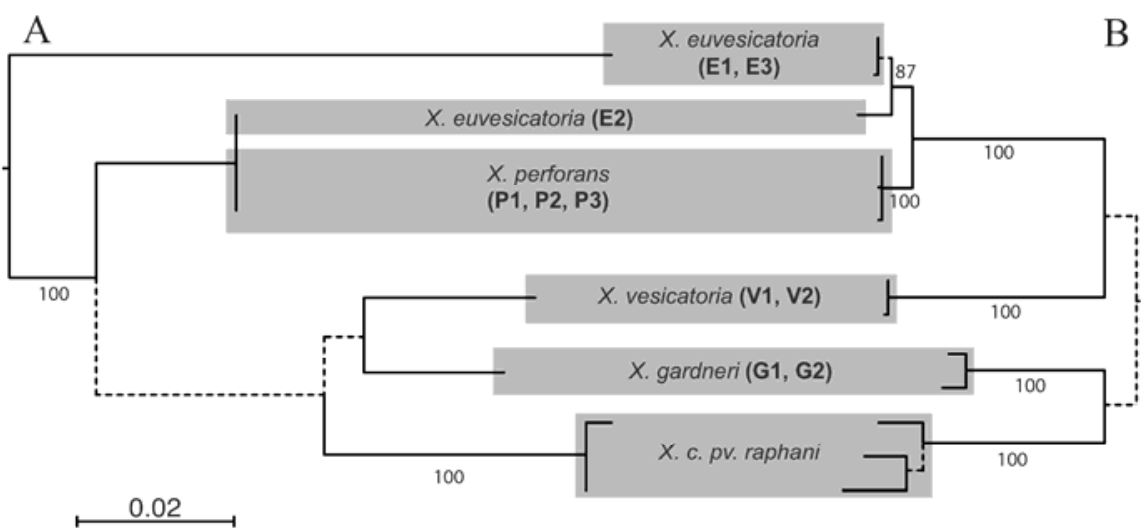

Fig. 3. Maximum likelihood tree based on concatenated $a t p D$, dnaK, efp, and $g y r B$ partial sequences, showing the relationships between Xanthomonas genospecies associated with bacterial spot of tomato and pepper. A, Tree based on the 309-bp atpD sequence identified by the RDP package as a recombinant region in some Xanthomonas euvesicatoria strains (sequence type [ST] E1 and ST E3). B, Tree based on the concatenated sequence deleted of the recombinant region. Branches with bootstrap values lower than $80 \%$ are represented by dotted lines.
Strains originating from Madagascar and Réunion had sequences that were totally identical to that of two strains (CFBP 1545 and NCPPB 3311) originating from Europe, whatever the gene portion (ST V2). This ST differed from ST V1 on the basis of two SNPs on the gyrB gene portion.

The three reference strains of $X$. campestris pv. raphani were identified as three different STs. With a single exception (CFBP 5827 versus CFBP 5828 for the efp gene portion), each strain was distinguishable whatever the assayed gene based on 1 to 13 SNPs. No strain originating from the SWIO region was genetically related to this pathovar.

Pathogenicity tests. The three reference strains of $X$. campestris pv. raphani produced typical leaf lesions whatever the radish cultivar assayed. All other strains were pathogenic to at least one solanaceous species (Table 1). Lesions first appeared as small water-soaked spots that enlarged slightly and became necrotic over time, whatever the inoculated plant species. All assayed strains identified as $X$. perforans and $X$. vesicatoria were only pathogenic to tomato. Lesions on inoculated leaves were first observed 4 to 6 and 3 to 5 dai for strains of $X$. perforans and $X$. vesicatoria, respectively. Mean population sizes recovered from leaf lesions ranged from $6 \times 10^{6}$ to $5 \times 10^{7}$ and from $3 \times 10^{6}$ to $2 \times 10^{7} \mathrm{CFU} / \mathrm{lesion}$, respectively. No visible symptom or hypersensitive responselike reaction was observed on either of the pepper cultivars for strains of $X$. perforans and $X$. vesicatoria.

All strains identified as $X$. gardneri produced lesions on tomato cv. Marmande and pepper cvs. Yolo Wonder and Aiguille. Leaf lesions started to develop 3 to 5 dai, whatever the cultivar. Mean population sizes recovered from leaf lesions ranged from $1 \times 10^{7}$ to $4 \times 10^{7}, 3 \times 10^{7}$ to $2 \times 10^{8}$, and $2 \times 10^{7}$ to $7 \times 10^{7} \mathrm{CFU} /$ lesion for tomato cv. Marmande and pepper cvs. Yolo Wonder and Aiguille, respectively.

The pathogenicity profiles observed for the $X$. euvesicatoria species were more variable among strains. All strains identified as $X$. euvesicatoria that originated from the SWIO region $(n=72)$ produced lesions on tomato cv. Marmande and pepper cv. Yolo Wonder, species for which lesions were first observed 3 to 5 dai. In contrast, differential pathogenicity reactions were recorded when pepper cv. Aiguille was inoculated with strains of $X$. euvesicatoria. Nine strains produced no visible reactions in response to inoculations. This was recorded for several strains originating from the Comoros and Réunion and also for the type strain of $X$. euvesicatoria.

On pepper cv. Aiguille, strains that produced lesions had mean population sizes per lesion ranging from $6 \times 10^{6}$ to $4 \times 10^{8}$ $\mathrm{CFU} /$ lesion, suggestive of compatible interactions. Mean population sizes per le- 
sion on pepper cv. Yolo Wonder ranged from $2 \times 10^{7}$ to $5 \times 10^{8} \mathrm{CFU} /$ lesion. On tomato, population sizes were more heterogeneous and differed significantly $(P<$ $0.0001)$ among strains. The largest population sizes (with means approximating $1 \times$ $10^{8} \mathrm{CFU} /$ lesion and significantly differing from those of other strains) were reproducibly recovered from lesions caused by some strains isolated from tomato and originating from the Comoros and Réunion (Table 2). Such strains were the ones to be avirulent on pepper cv. Aiguille. In contrast, lower population sizes (with means ranging from $8 \times 10^{4}$ to $2 \times 10^{7}$ CFU/lesion) were recovered from lesions caused by other strains. Strains that displayed the lowest population sizes when inoculated on tomato were isolated from diseased pepper samples in Mauritius, Réunion, and the Seychelles (Table 2). No clear-cut differences in the morphology of leaf lesions or the speed of lesion development after inoculation were recorded among strains of either group.

\section{DISCUSSION}

In the present study, Xanthomonas strains responsible for outbreaks of BSTP in the SWIO region were assigned to species using AFLP. AFLP has already been extensively used for investigating the species classification in the genus Xanthomonas $(2,10,17,40,43)$, the intrapathovar assessment of genetic diversity $(1,6,9,41)$, and addressing epidemiology-related questions $(16,34)$. The examination of genetic distances of strains from the SWIO region to type or pathotype strains of $X$. campestris pv. raphani, $X$. euvesicatoria, $X$. gardneri, $X$. perforans, and $X$. vesicatoria meant that identification at the species level was unambiguous. Genetic distances calculated among type strains were mostly consistent with their separation into distinct species. The one exception was between $X$. euvesicatoria and X. perforans, consistent with other recent data suggesting the synonymy between these species $(33,51)$. More data are needed to examine the question further.

MLSA data suggested that synonymous SNPs were the primary source of sequence variation on the four targeted housekeeping genes. However, a recombination event was detected on the atpD gene portion for most (45/51) strains of $X$. euvesicatoria. We hypothesize that recombination oc-

Table 1. Pathogenicity profiles based on leaf infiltrations of 72 xanthomonad strains associated with bacterial spot of tomato and pepper in the southwest Indian Ocean region

\begin{tabular}{lccc}
\hline & \multicolumn{3}{c}{ Inoculated host species and cultivar } \\
\cline { 2 - 4 } Xanthomonas spp. & $\begin{array}{c}\text { Tomato cv. } \\
\text { Marmande }\end{array}$ & $\begin{array}{c}\text { Pepper cv. } \\
\text { Yolo Wonder }\end{array}$ & $\begin{array}{c}\text { Pepper cv. } \\
\text { Aiguille }\end{array}$ \\
\hline Xanthomonas euvesicatoria $(n=38)$ & + & + & + \\
X. euvesicatoria $(n=9)$ & + & + & - \\
X. perforans $(n=11)$ & + & - & - \\
X. gardneri $(n=9)$ & + & + & + \\
X. vesicatoria $(n=5)$ & + & - & - \\
\hline
\end{tabular}

curred on this species from an unknown, distantly related Xanthomonas sp. The nucleotidic sequence of this region did not match that of other species causing BSTP, suggesting that these were probably not involved in the recombination event (or the recombinant region is a mosaic structure resulting from numerous independent recombination events, which is improbable). A blast search using the recombinant region as the query did not allow identification of the species or pathovar, which may have been involved in the recombination event. The phylogenetic tree obtained when the recombinant region was deleted from the concatenated alignment indicated a very close relatedness between $X$. euvesicatoria and $X$. perforans, consistent with AFLP data. Our results illustrate the limitations of single-gene-based phylogenies, which are more prone than MLSA to erroneous estimations of relatedness among similar species as a result of interspecies recombination (15). MLSA accurately identified strains associated with BSTP at the species level. Our results suggest that at least two genes (dnaK and gyrB are recommended) should be targeted for routine identification of BSTP-causing xanthomonads, although the classification of new strains into the ST system described herein would require the use of the complete scheme.

Two to three sequence types were identified per species and they corresponded to strains that formed robust clusters based on AFLP data. One major advantage of MLSA or multilocus sequence typing over genotyping techniques, such as AFLP or rep-PCR, is that it allows more robust interlaboratory comparisons, leading to the possible development of Internet databases

Table 2. Examples of pathogenicity and population sizes recorded from leaf lesions 25 days after the inoculation of two host species with Xanthomonas euvesicatoria

\begin{tabular}{|c|c|c|c|c|c|c|}
\hline \multirow[b]{2}{*}{ Strain } & \multirow[b]{2}{*}{ Host of isolation } & \multirow[b]{2}{*}{ Country } & \multicolumn{2}{|c|}{ Tomato cv. Marmande } & \multicolumn{2}{|c|}{ Pepper cv. Aiguille } \\
\hline & & & Pathogenicity $^{x}$ & Population size $^{y}$ & Pathogenicity $^{x}$ & Population size $^{\mathrm{y}}$ \\
\hline NCPPB $2968^{z}$ & Capsicum frutescens & United States & $+(4-6)$ & $6.94(0.52) \mathrm{d}$ & - & NA \\
\hline LA84-1 & C. аппиит & Comoros & $+(4-7)$ & $7.11(0.35) \mathrm{d}$ & $+(9-11)$ & 7.47 (0.78) bcdef \\
\hline LA88-2 & C. аппиит & Comoros & $+(3)$ & $6.98(0.27) \mathrm{d}$ & $+(9-13)$ & $6.84(0.46) \mathrm{f}$ \\
\hline LA88-4 & C. аппиит & Comoros & $+(3-4)$ & $7.18(0.34) \mathrm{cd}$ & $+(7-9)$ & $7.33(0.56) \mathrm{e}$ \\
\hline LE82-4 & C. аппиит & Mauritius & $+(4)$ & $5.26(0.58) \mathrm{g}$ & $+(5-6)$ & $8.29(0.10) \mathrm{ab}$ \\
\hline LE83-1 & C. аппиит & Mauritius & $+(4)$ & $6.07(0.59) \mathrm{e}$ & $+(5)$ & $8.12(0.25) \mathrm{c}$ \\
\hline LE84 & C. аппиит & Mauritius & $+(3-5)$ & $5.40(0.41) \mathrm{g}$ & $+(6-7)$ & $7.64(0.46) \mathrm{cd}$ \\
\hline LA127-1 & C. аппиит & Réunion & $+(4-6)$ & $5.77(0.45) \mathrm{f}$ & $+(6)$ & $8.51(0.46) \mathrm{a}$ \\
\hline LA127-2 & C. аппиит & Réunion & $+(4)$ & $5.56(0.55) \mathrm{fg}$ & $+(4-5)$ & $7.51(0.44) \mathrm{de}$ \\
\hline LD128-1 & C. аппиит & Seychelles & $+(4-5)$ & $6.30(0.62) \mathrm{e}$ & $+(5-7)$ & $7.44(0.40) \mathrm{de}$ \\
\hline LD128-2 & C. аппиит & Seychelles & $+(4-5)$ & $5.68(0.48) \mathrm{f}$ & $+(7-9)$ & $6.82(0.56) \mathrm{f}$ \\
\hline LB226-2 & Solanum lycopersicum & Comoros & $+(3-4)$ & $6.98(0.41) \mathrm{d}$ & $+(7-12)$ & $7.71(0.35) \mathrm{cde}$ \\
\hline LB102-1 & S. lycopersicum & Seychelles & $+(4-5)$ & $7.31(0.43) \mathrm{c}$ & $+(11-13)$ & $7.85(0.24) \mathrm{c}$ \\
\hline LB215-2 & S. lycopersicum & Comoros & $+(3-4)$ & $8.08(0.48)$ a & - & NA \\
\hline JW6 & S. lycopersicum & Réunion & $+(3-4)$ & $8.12(0.44) \mathrm{a}$ & - & NA \\
\hline JW7 & S. lycopersicum & Réunion & $+(3-4)$ & $7.97(0.44)$ a & - & NA \\
\hline LB230-1 & S. lycopersicum & Réunion & $+(3-5)$ & $7.77(0.38) \mathrm{b}$ & - & NA \\
\hline LB230-2 & S. lycopersicum & Réunion & $+(3-5)$ & $7.95(0.41) \mathrm{a}$ & - & NA \\
\hline
\end{tabular}

${ }^{x}$ Number of days after inoculation (dai) for record of initial lesion; $+=$ development of lesions, $-=$ no development of lesions, and NA $=$ not available.

y Population sizes were determined on KC semiselective medium (37), and 8 to 12 lesions per strain-host combination were used for population size assessment. Each value represents log-transformed CFU lesion ${ }^{-1}$. Values in parentheses are standard deviations. Strain comparisons were based on WilcoxonMann-Whitney tests. Population size values with the same letters did not differ significantly $(P=0.05)$.

z Type strain. 
(15). Such tools could markedly improve international surveillance of clones associated with major plant bacterial diseases.

This study provides the first comprehensive description of the status of Xanthomonas spp. causing BSTP in the SWIO region. Although the analysis of more strains will be needed in future for a more thorough description of the precise sanitary status of all the islands in the region, a wide genetic diversity of strains associated with BSTP was recorded. Only $X$. campestris pv. raphani was not detected. Our study further amends the data produced by Jones et al. (21) a decade ago, which suggested that only $X$. vesicatoria was present in the SWIO region.

Strains originating from the SWIO region and causing BSTP had pathological characteristics, which agreed with data available in the literature. $X$. perforans and $X$. vesicatoria strains were isolated solely from tomato and were pathogenic to this species but not to pepper, which is consistent with previous data $(7,42)$. Strains identified as $X$. gardneri were isolated from diseased samples of tomato and pepper and were pathogenic to both species, consistent with earlier data from Brazil (39). For these three species, no marked infraspecific pathogenic variations were observed among strains from the SWIO region. In contrast, three different pathogenicity profiles were identified among strains of $X$. euvesicatoria. A common feature was that all $X$. euvesicatoria strains shared pathogenicity to pepper cv. Yolo Wonder, with no marked quantitative variations among strains (data not shown). The first group included strains isolated from tomato in Réunion over at least 6 years, and from the Comoros. Although these strains did not differ in terms of leaf lesion morphology or length of the pathogenic latency period when inoculated to tomato cv. Marmande, they survived in lesions at population sizes significantly larger than all other assayed strains. Moreover, they were avirulent on pepper cv. Aiguille, although this local cultivar is not known for having pepper resistance genes in its genome. The second group included strains isolated from tomato in the Comoros and the Seychelles. These strains were pathogenic to tomato $\mathrm{cv}$. Marmande and pepper cv. Aiguille. The third group included strains isolated from pepper in the Comoros, Mauritius, Réunion, and the Seychelles. These strains were pathogenic to tomato cv. Marmande and pepper cv. Aiguille. Most strains from this group multiplied to low population sizes $(\leq 2 \times$ $10^{6} \mathrm{CFU} /$ lesion) when inoculated to tomato cv. Marmande. This group of strains was genetically heterogeneous, as determined by AFLP. All strains identified as ST E3 by MLSA were weakly aggressive on tomato cv. Marmande, although a few strains identified as ST E1 were, too. To our knowledge, no tomato or pepper culti- vars bearing resistance genes to the causal agents of BSTP are grown commercially in the SWIO region.

The species and haplotype composition in the SWIO region populations probably reflects the history of pathogen introductions through one or several pathways, such as contaminated seed $(3,20)$. For $X$. vesicatoria, it was found that, based on AFLP, strains isolated in Madagascar and Réunion were most closely related to strains originating from France and Italy. These strains formed a robust cluster easily distinguishable from another group that included the $X$. vesicatoria type strain. MLSA data consistently identified the strains originating from the SWIO region as the same ST as strains from France and Italy. Tomato and pepper seed are an important pathway for the introduction of BSTP-causing xanthomonads in the SWIO region. In Réunion, the application of a $\mathrm{CE}$ quality standard for tomato and pepper seedlings has contributed to a lesser incidence of seedborne bacterial pathogens in the field. Similar certification schemes are implemented or currently being developed in other countries in the SWIO region.

\section{ACKNOWLEDGMENTS}

The Programme Régional de Protection des Végétaux (PRPV) was funded by the 8th European Development Fund (contract PRPV-COI/FED/05007) under the authority of the Indian Ocean Commission. The European Regional Development Fund of the European Union, Conseil Régional de La Réunion, and CIRAD also provided financial support. We thank P. Prior, C. Vernière, M. Le Saux, V. Grimault, and M. Roux-Cuvelier for helpful discussion or manuscript review before submission; S. Benimadhu, D. Cuppels, B. Hostachy, P. Prior, and G. Wuster for providing us with diseased plant material or bacterial strains; and C. Boyer, W. Grondin, A. Laurent, V. Ledoux , and K. Vital for technical assistance.

\section{LITERATURE CITED}

1. Ah-You, N., Gagnevin, L., Chiroleu, F., Jouen, E., Neto, J. R., and Pruvost, O. 2007. Pathological variations within Xanthomonas campestris pv. mangiferaeindicae support its separation into three distinct pathovars that can be distinguished by amplified fragment length polymorphism. Phytopathology 97:1568-1577.

2. Ah-You, N., Gagnevin, L., Grimont, P. A. D., Brisse, S., Nesme, X., Chiroleu, F., Bui Thi Ngoc, L., Jouen, E., Lefeuvre, P., Vernière, C., and Pruvost, O. 2009. Polyphasic characterization of xanthomonads pathogenic to Anacardiaceae and their relatedness to different Xanthomonas species. Int. J. Syst. Evol. Microbiol. 59:306-318.

3. Bashan, Y., and Okon, Y. 1986. Internal and external infections of fruits and seeds of peppers by Xanthomonas campestris pv. vesicatoria. Can. J. Bot. 64:2865-2871.

4. Benjamini, Y., and Hochberg, Y. 1995. Controlling the false discovery rate: a practical and powerful approach to multiple testing. J. R. Stat. Soc. Ser. B 57:289-300.

5. Boni, M. F., Posada, D., and Feldman, M. W. 2007. An exact nonparametric method for inferring mosaic structure in sequence triplets. Genetics 176:1035-1047.

6. Boudon, S., Manceau, C., and Notteghem, J. L. 2005. Structure and origin of Xanthomonas arboricola pv. pruni populations causing bacterial spot of stone fruit trees in Western
Europe. Phytopathology 95:1081-1088.

7. Bouzar, H., Jones, J. B., Stall, R. E., Hodge, N. C., Minsavage, G. V., Benedict, A. A., and Alvarez, A. M. 1994. Physiological, chemical, serological, and pathogenic analyses of a worldwide collection of Xanthomonas campestris pv. vesicatoria strains. Phytopathology 84: 663-671.

8. Bouzar, H., Jones, J. B., Stall, R. E., Louws, F. J., Schneider, M., Rademaker, J. L. W., De Bruijn, F. J., and Jackson, L. E. 1999. Multiphasic analysis of xanthomonads causing bacterial spot disease on tomato and pepper in the Caribbean and Central America: evidence for common lineages within and between countries. Phytopathology 89:328-335.

9. Bui Thi Ngoc, L., Vernière, C., Jarne, P., Brisse, S., Guérin, F., Boutry, S., Gagnevin, L., and Pruvost, O. 2009. From local surveys to global surveillance: three high throughput genotyping methods for the epidemiological monitoring of Xanthomonas citri pv. citri pathotypes. Appl. Environ. Microbiol. 75:1173-1184

10. Bui Thi Ngoc, L., Vernière, C., Jouen, E., AhYou, N., Lefeuvre, P., Chiroleu, F., Gagnevin, L., and Pruvost, O. 2010. Amplified fragment length polymorphism and multilocus sequence analysis-based genotypic relatedness among pathogenic variants of Xanthomonas citri pv. citri and Xanthomonas campestris pv. bilvae. Int. J. Syst. Evol. Microbiol. 60:515-525.

11. Fargier, E., and Manceau, C. 2007. Pathogenicity assays restrict the species Xanthomonas campestris into three pathovars and reveal nine races within $X$. campestris pv. campestris. Plant Pathol. 56:805-818.

12. Gascuel, O. 1997. Concerning the NJ algorithm and its unweighted version UNJ. Pages 149-171 in: Mathematical Hierarchies and Biology. B. Mirkin, F. R. McMorris, F. Roberts, and A. Rzhetsky, eds. American Mathematical Society, Providence, RI.

13. Gibbs, M. J., Armstrong, J. S., and Gibbs, A. J. 2000. Sister-scanning: a Monte Carlo procedure for assessing signals in recombinant sequences. Bioinformatics 16:573-582.

14. Guindon, S., and Gascuel, O. 2003. A simple, fast, and accurate algorithm to estimate large phylogenies by maximum likelihood. Syst. Biol. 52:696-704.

15. Hanage, W. P., Fraser, C., and Spratt, B. G. 2006. Sequences, sequence clusters and bacterial species. Philos. Trans. R. Soc. Ser. B 361:1917-1927.

16. Humeau, L., Roumagnac, P., Picard, Y., Robène-Soustrade, I., Chiroleu, F., Gagnevin, L., and Pruvost, O. 2006. Quantitative and molecular epidemiology of bacterial blight of onion in seed production fields. Phytopathology 96:1345-1354.

17. Janssen, P., Coopman, R., Huys, G., Swings, J., Bleeker, M., Vos, P., Zabeau, M., and Kersters, K. 1996. Evaluation of the DNA fingerprinting method AFLP as a new tool in bacterial taxonomy. Microbiology 142:1881-1893.

18. Jones, J. B., Lacy, G. H., Bouzar, H., Minsavage, G. V., Stall, R. E., and Schaad, N. W. 2005. Bacterial spot. Worldwide distribution, importance and review Acta Hortic. 695:27-33.

19. Jones, J. B., Lacy, G. H., Bouzar, H., Stall, R. E., and Schaad, N. W. 2004. Reclassification of the xanthomonads associated with bacterial spot disease of tomato and pepper. Syst. Appl. Microbiol. 27:755-762.

20. Jones, J. B., Pohronezny, K. L., Stall, R. E., and Jones, J. P. 1986. Survival of Xanthomonas campestris pv. vesicatoria in Florida on tomato crop residue, weeds, seeds, and volunteer tomato plants. Phytopathology 76:430-434.

21. Jones, J. B., Stall, R. E., and Bouzar, H. 1998. Diversity among xanthomonads pathogenic on pepper and tomato. Annu. Rev. Phytopathol. 36:41-58

22. Kuflu, K. M., and Cuppels, D. A. 1997. Devel- 
opment of a diagnostic DNA probe for xanthomonads causing bacterial spot of peppers and tomatoes. Appl. Environ. Microbiol. 63: $4462-4470$

23. Louws, F. J., Fulbright, D. W., Stephens, C. T., and Debruijn, F. J. 1995. Differentiation of genomic structure by rep-PCR fingerprinting to rapidly classify Xanthomonas campestris pv. vesicatoria. Phytopathology 85:528-536.

24. Martin, D., and Rybicki, E. 2000. RDP: detection of recombination amongst aligned sequences. Bioinformatics 16:562-563.

25. Martin, D. P., Posada, D., Crandall, K. A., and Williamson, C. 2005. A modified bootscan algorithm for automated identification of recombinant sequences and recombination breakpoints. AIDS Res. Hum. Retrovir. 21:98-102.

26. Martin, D. P., Williamson, C., and Posada, D. 2005. RDP2: recombination detection and analysis from sequence alignments. Bioinformatics 21:260-262.

27. Maynard-Smith, J. 1992. Analyzing the mosaic structure of genes. J. Mol. Evol. 34:126-129.

28. Mougel, C., Thioulouse, J., Perrière, G., and Nesme, X. 2002. A mathematical method for determining genome divergence and species delineation using AFLP. Int. J. Syst. Evol. Microbiol. 52:573-586.

29. Nei, M., and Gojobori, T. 1986. Simple methods for estimating the numbers of synonymous and nonsynonymous nucleotide substitutions. Mol. Biol. Evol. 3:418-426.

30. Obradovic, A., Mavridis, A., Rudolph, K., Janse, J. D., and Arsenijevic, M. 2004. Characterization and PCR-based typing of Xanthomonas campestris pv. vesicatoria from peppers and tomatoes in Serbia. Eur. J. Plant Pathol. 110:285-292.

31. Padidam, M., Sawyer, S., and Fauquet, C. M. 1999. Possible emergence of new geminiviruses by frequent recombination. Virology 265:218-225

32. Paradis, E., Claude, J., and Strimmer, K. 2004. APE: analyses of phylogenetics and evolution in R language. Bioinformatics 20:289-290.

33. Parkinson, N., Aritua, V., Heeney, J., Cowie, C., Bew, J., and Stead, D. 2007. Phylogenetic analysis of Xanthomonas species by comparison of partial gyrase B gene sequences. Int. J. Syst. Evol. Microbiol. 57:2881-2887.
34. Picard, Y., Roumagnac, P., Legrand, D., Humeau, L., Robène-Soustrade, I., Chiroleu, F., Gagnevin, L., and Pruvost, O. 2008. Polyphasic characterization of Xanthomonas axonopodis pv. allii associated with outbreaks of bacterial blight on three Allium species in the Mascarene archipelago. Phytopathology 98:919-925.

35. Portier, P., Fischer-Le Saux, M., Mougel, C., Lerondelle, C., Chapulliot, D., Thioulouse, J., and Nesme, X. 2006. Identification of genomic species in Agrobacterium biovar 1 by AFLP genomic markers. Appl. Environ. Microbiol. 72:7123-7131.

36. Posada, D., and Crandall, K. A. 2001. Evaluation of methods for detecting recombination from DNA sequences: computer simulations. Proc. Natl. Acad. Sci. USA 98:13757-13762.

37. Pruvost, O., Roumagnac, P., Gaube, C., Chiroleu, F., and Gagnevin, L. 2005. New media for the semi-selective isolation and enumeration of Xanthomonas campestris pv. mangiferaeindicae, the causal agent of mango bacterial black spot. J. Appl. Microbiol. 99:803-815.

38. Punina, N. V., Ignatov, A. N., Pekhtereva, E. S., Kornev, K. P., Matveeva, E. V., Polityko, N. I., and Schaad, N. W. 2009. Occurrence of Xanthomonas campestris pv. raphani on tomato plants in the Russian federation. Acta Hortic. 808:287-290.

39. Quezado-Duval, A. M., Leite Jr., R. P., Truffi, D., and Camargo, L. E. A. 2004. Outbreaks of bacterial spot caused by Xanthomonas gardneri on processing tomato in central-west Brazil. Plant Dis. 88:157-161.

40. Rademaker, J. L. W., Hoste, B., Louws, F. J., Kersters, K., Swings, J., Vauterin, L., Vauterin, P., and De Bruijn, F. J. 2000. Comparison of AFLP and rep-PCR genomic fingerprinting with DNA-DNA homology studies: Xanthomonas as a model system. Int. J. Syst. Evol. Microbiol. 50:665-677.

41. Restrepo, S., Duque, M., Tohme, J., and Verdier, V. 1999. AFLP fingerprinting: an efficient technique for detecting genetic variation of Xanthomonas axonopodis pv. manihotis. Microbiology 145:107-114.

42. Robbins, M. D., Darrigues, A., Sim, S. C., Mohammed Abu Taher Masud, and Francis, D. M. 2009. Characterization of hypersensitive resistance to bacterial spot race $\mathrm{T} 3$ (Xanthomonas perforans) from tomato accession $\mathrm{P}$ 128216. Phytopathology 99:1037-1044.

43. Roumagnac, P., Gagnevin, L., Gardan, L., Sutra, L., Manceau, C., Dickstein, E. R., Jones, J. B., Rott, P., and Pruvost, O. 2004. Polyphasic characterization of xanthomonads isolated from onion, garlic and Welsh onion (Allium spp.) and their relatedness to different Xanthomonas species. Int. J. Syst. Evol. Microbiol. 54:15-24

44. Roumagnac, $\mathrm{P}$, Gagnevin, $\mathrm{L}$, and Pruvost, $\mathrm{O}$ 2000. Detection of Xanthomonas sp., the causal agent of onion bacterial blight, in onion seeds using a newly developed semi-selective isolation medium. Eur. J. Plant Pathol. 106:867-877.

45. Saitou, N., and Nei, M. 1987. The neighborjoining method: A new method for reconstructing phylogenetic trees. Mol. Biol. Evol. 4:406425.

46. Stall, R. E., Beaulieu, C., Egel, D., Hodge, N. C., Leite, R. P., Minsavage, G. V., Bouzar, H. Jones, J. B., Alvarez, A. M., and Benedict, A. A. 1994. Two genetically diverse groups of strains are included in Xanthomonas campestris pv. vesicatoria. Int. J. Syst. Bacteriol. 44:47-53.

47. Tamura, K., Dudley, J., Nei, M., and Kumar, S. 2007. MEGA4: molecular evolutionary genetics analysis (MEGA) software version 4.0. Mol. Biol. Evol. 24:1596-1599.

48. Thompson, J. D., Gibson, T. J., Plewniak, F., Jeanmougin, F., and Higgins, D. G. 1997. The Clustal $\times$ Windows interface: Flexible strategies for multiple sequence alignment aided by quality analysis tools. Nucleic Acids Res. 25:4876-4882.

49. Vicente, J. G., Everett, B., and Roberts, S. J. 2006. Identification of isolates that cause a leaf spot disease of brassicas as Xanthomonas campestris pv. raphani and pathogenic and genetic comparison with related pathovars. Phytopathology 96:735-745.

50. White, H. E. 1930. Bacterial spot of radish and turnip. Phytopathology 20:653-662.

51. Young, J. M., Park, D. C., Shearman, H. M., and Fargier, E. 2008. A multilocus sequence analysis of the genus Xanthomonas. Syst. Appl. Microbiol. 31:366-377. 